\title{
Activated Carbons for Arsenic Removal from Natural Waters and Wastewaters: A Review
}

\author{
Elie Meez ${ }^{1}$, Athanasia K. Tolkou ${ }^{1,2} \mathbb{D}$, Dimitrios A. Giannakoudakis ${ }^{2} \mathbb{D}$, Ioannis A. Katsoyiannis ${ }^{2, *}$ \\ and George Z. Kyzas ${ }^{1, *(D)}$ \\ 1 Department of Chemistry, International Hellenic University, 65404 Kavala, Greece; \\ eliemouez@gmail.com (E.M.); tolkatha@chem.auth.gr (A.K.T.) \\ 2 Laboratory of Chemical and Environmental Technology, Department of Chemistry, Aristotle University of \\ Thessaloniki, 54124 Thessaloniki, Greece; dagchem@gmail.com \\ * Correspondence: katsogia@chem.auth.gr (I.A.K.); kyzas@chem.ihu.gr (G.Z.K.)
}

check for updates

Citation: Meez, E.; Tolkou, A.K.; Giannakoudakis, D.A.; Katsoyiannis, I.A.; Kyzas, G.Z. Activated Carbons for Arsenic Removal from Natural Waters and Wastewaters: A Review. Water 2021, 13, 2982. https:// doi.org/10.3390/w13212982

Academic Editor: Carmen Teodosiu

Received: 14 September 2021

Accepted: 18 October 2021

Published: 22 October 2021

Publisher's Note: MDPI stays neutral with regard to jurisdictional claims in published maps and institutional affiliations.

Copyright: (c) 2021 by the authors. Licensee MDPI, Basel, Switzerland. This article is an open access article distributed under the terms and conditions of the Creative Commons Attribution (CC BY) license (https:// creativecommons.org/licenses/by/ $4.0 /)$.

\begin{abstract}
The arsenic pollution of waters and wastewaters is concerning many countries across the world, and because of the effects of arsenic on human health, its removal from waters is of great importance. Adsorption using functionalized activated carbons as a technique for the removal of arsenic from water streams has gained great attention. In the present review, we summarize synthesis technologies, the characterization of materials and arsenic removal capacity, and we clarify the parameters which play a critical role in the removal of arsenic, such as the $\mathrm{pH}$ value of the water, the active group in the functionalization and temperature. The review article concludes that most of the experimental data fit both Langmuir and Freundlich isotherms. In this review, the recyclability and reuse of the materials are also reported, and the findings show that for both arsenite and arsenate, even after several adsorption cycles, the material can be further used as an efficient adsorbent for arsenic removal.
\end{abstract}

Keywords: arsenic; adsorption; removal; oxidation

\section{Introduction}

Worldwide, more than 750 million people have no access to safe drinking water [1], and more than 250 million inhabitants are regularly exposed to water contaminated with arsenic [2,3]. Moreover, according to recent estimations, more arsenic-contaminated areas are expected to be discovered, such as recently in the case of Pakistan [4]. Furthermore, in Europe, there are many areas affected by arsenic, impacting a population of about 1.5 million people [5].

Taking into consideration the health effects of arsenic for humans, the risk of its presence in drinking water and the way in which it is being treated, the WHO established a guideline value of arsenic in drinking water of $10 \mu \mathrm{g} / \mathrm{L}$ in 1993, which is the limit of arsenic in drinking water in the European Union and also in the United States of America [6,7]. However, many countries still accept a maximum arsenic contaminant level in their drinking water at the value of $50 \mu \mathrm{g} / \mathrm{L}$, such as Bangladesh [6,8], India [9] and Cambodia [10].

Most of the arsenic-related problems for humans and the environment are due to geogenic processes, such as reductive dissolution. However, anthropogenic activities such as mining, the combustion of fossil fuels or even the use of arsenic in agriculture (found within pesticides, for example) lead to the additional input of arsenic compounds in the environment, mainly in water bodies [11].

Arsenic concentrations found in groundwaters range from less than $0.5 \mu \mathrm{g} / \mathrm{L}$ up to $50 \mathrm{mg} / \mathrm{L}$ [12], with some findings stating that numerous water sources contain arsenic concentrations more than $50 \mu \mathrm{g} / \mathrm{L}[12,13]$. There are many factors that are responsible for the presence of arsenic in groundwater, and these factors include the characteristics of the 
aquifer itself, organic content and the grain size of the sediments in the aquifer alongside other processes such as ion exchange and adsorption-desorption cycles. Between all the water sources previously mentioned, arsenic can naturally occur in high concentrations and in a wide range in groundwater, and this is due to the interactions between the water and the rocks, which favor the mobilization of arsenic, leading to elevated arsenic concentrations [12]. In addition, human activities such as mining can release to the environment much higher arsenic quantities and cause heavier pollution than naturally occurring arsenic, thus creating a larger issue that needs to be resolved [3-6,8,11].

Arsenic is found in waters mainly in its inorganic forms: trivalent, As (III) and pentavalent arsenic, As (V), known as arsenite and arsenate, respectively [14]. Arsenite is 10 times more toxic than arsenate $[15,16]$. Figure 1 shows the speciation of As (III) and As (V) as function of $\mathrm{pH}$. Arsenic is considered to be highly toxic and can have major health impacts if humans are exposed for long periods above certain concentration limits. For instance, exposure to arsenic by the consumption of drinking water for a long time is related to a chronic illness that is linked to the development of cancer. Moreover, the exposure of pregnant women to arsenic has caused severe problems regarding fetal development through malfunctions and has led eventually to abortion [17]. Therefore, arsenic removal from drinking water sources is a matter of great concern for the world population.

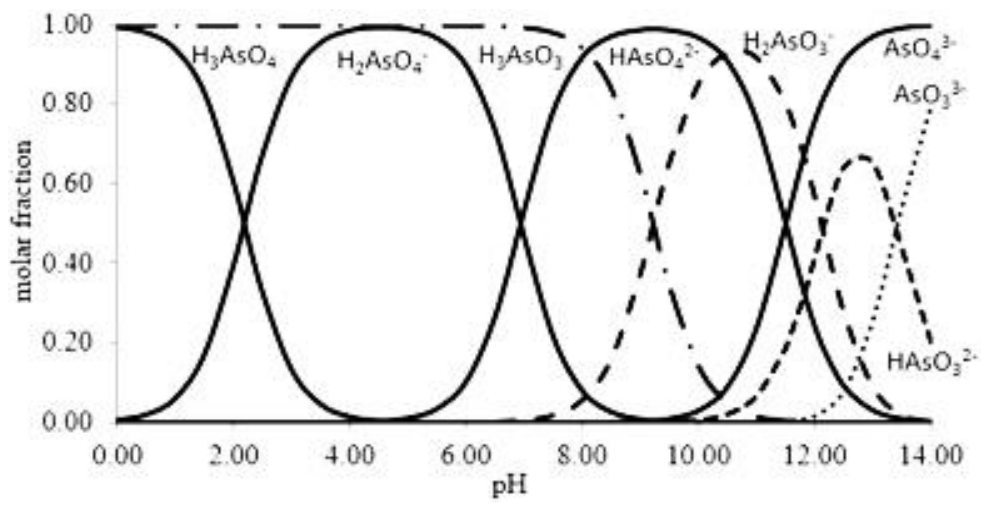

Figure 1. Speciation of As (III) and As (V) as a function of pH. Reprinted from Ungureanu et al. [14] Copyright 2021 Elsevier (Ungureanu et al., 2015).

It has been well demonstrated that, in Europe and other developed countries, almost all arsenic violations are observed in small communities with a population of fewer than 1000 people. Large drinking water plants in Northern and Central Europe either use alternative arsenic-free water resources or they apply conventional high-tech removal methods such as coagulation/filtration, activated alumina and ion exchange, Granular Ferric Hydroxide (GFH) or Bayoxide (E33) [3]. Smaller towns, communities and individual users in rural areas often rely on local water resources, and removal methods developed for large plants are not applicable because of the high operational and capital costs. In addition, these removal units are often too complicated to operate, or their use is limited by the local water composition. In Hungary, Romania and Northern Greece, the population in the affected regions uses groundwater usually without any treatment, or treatment is based only on simple aeration and filtration, which is usually not sufficient for the efficient removal of these hazardous substances. Consequently, small drinking water systems face the difficult challenge of providing a safe and sufficient supply of water at a reasonable cost. In Bangladesh and West Bengal, a number of simple treatments has been developed for use (e.g., oxidation of As (III) with chemical oxidants or with sunlight followed by precipitation with naturally present or added iron and aluminum salts, removal with zerovalent iron and sorption in prefabricated filters with iron and aluminum oxide sorbents). However, there are still open issues regarding the applicability of these technologies as they present several limitations, especially when iron and manganese are not present, or they are present at low concentrations. 
A major process that has been used for more than a century for water purification is adsorption. Therefore, the development and application of new adsorbents has been studied intensively over the past years. The performance of any adsorbent depends strongly on the chemical form of the adsorbate that is under investigation for removal. Therefore, it is essential to understand the behavior of arsenic compounds in aqueous solutions and their structure in order to provide the best adsorbent for the efficient removal of arsenic from waters. There are plenty of materials from several sources that have been studied as adsorbents for the removal of different heavy metals from water sources or wastewaters such as natural materials, wastes and synthetic adsorbents, and all of those can be used in both treated and untreated forms. The main focus on adsorption for cleanup procedures is related to the advantages that are provided by the adsorption itself, and this includes the simplicity of implementation and operation, the low cost associated with the production process, minimal waste and sludge production and most importantly the possibility of regeneration or reuse for many cycles [18].

Activated carbon is one of the most common materials used in adsorption; it is used generally in water purification and can be provided either naturally or synthetically. In addition, activated carbon is implemented for adsorption purposes as a natural material, or it can go through treatment for surface modification. The reason activated carbon is mainly used in adsorption and for cleanup purposes in general is due to the many advantages that the activated carbon provides that could enhance the removal efficiency of heavy metals or other ions, and these advantages include a surface that is highly reactive and highly irregular alongside a high porosity and a large surface area. All these mentioned qualities are soughtafter when dealing with an adsorption process, which suggests activated carbon to be an exceptional material candidate for the removal of ions from water sources by adsorption. The use of activated carbon has been widely studied in the literature for the removal of several ions over the years, but recently, the potential of activated carbon to provide efficient removal for arsenic has attracted great interest, and many studies in the recent years have been conducted to investigate the behavior of activated carbon for arsenic removal.

Vitela-Rodriguez and Rangel-Mendez [19] tested the use of several activated carbons that were modified with hydroxide nanoparticles for the removal of arsenic content from natural waters that were taken from a well in Mexico. Their study aimed to determine the effect of temperature and $\mathrm{pH}$ on the adsorption process; in addition, the surface morphology of the modified activated carbon was evaluated alongside the kinetics and thermodynamics of the experiment [19]. Muñiz et al. [20] focused their investigations on using commercial activated carbon for the purpose of removing arsenic from natural well water from the state of Chihuahua; they used both raw and modified activated carbons in order to determine which materials exhibited the highest arsenic uptake [20]. Another study by Chen et al. focused on increasing the impregnation of iron into the activated carbon [21].

In the present review paper, several studies using activated carbon for the removal of arsenic ions are reviewed and discussed while providing an insight into the synthesis of these materials and their characterization. Moreover, the adsorption evaluation of these synthesized activated carbons is also reviewed with a special emphasis on the kinetics of the process, isotherms and the effect of $\mathrm{pH}$ and temperature. Finally, a section concerning regeneration and the use of some synthesized activated carbons for many cycles is provided and discussed.

The objective of this review paper is to present the findings from the literature and highlight the advancements of the newly prepared materials for more efficient arsenic removal by activated carbons and their modified alternatives. Although several reviews on arsenic removal have been published in the past, only a few of them have focused on the removal of arsenic by activated carbons and their modified alternatives. To the best of our knowledge, only one review paper [22] was found in our literature search that focused on arsenic removal by activated carbons. Therefore, this review is novel in the sense that it 
summarizes the findings from the last 5 years, during which a great advancement in the preparations, modifications, characterizations and applications has been achieved.

\section{Methodology}

To conduct this review, the following methodology was followed. First of all, we identified the subject, which was the use of activated carbons and their modifications for arsenic removal by adsorption. This was based on the fact that, during recent years, only one review paper was published focusing on arsenic removal by activated carbons, despite the numerous papers that have since been published. Then, we performed a literature search in databases such as Scopus, Pubmed and Sciencedirect and found the most representative articles, which in our view provided new advancements in the field. For this, we used among others the following keywords: arsenic, activated carbons, waste, wastewaters, modification, adsorption, oxidation, arsenic speciation and metal impregnation. The next step was to read carefully the selected papers and note down the most important information that we wanted to highlight in the review, comprising the methods of synthesis, characterization, application, models of adsorption, adsorption efficiencies and regeneration possibilities and efficiencies.

\section{Synthesis of the Materials}

Activated carbons applied for arsenic removal are in all cases modified by being functionalized with active groups, which enhance the removal of arsenic either by direct sorption or firstly by oxidation of As (III) and then the sorption of the resulting As(V). The major groups that have been used to modify AC are iron and manganese oxides and combinations of them, zirconium and other oxides, as shown in Table 1. A study by Xiong et al. [23] investigated the use of modified activated carbon by manganese dioxide and iron hydroxide for the adsorption of As (III) ions, where an appropriate amount of straw was ground into powder and then heated in a furnace at a rate of $10^{\circ} \mathrm{C} / \mathrm{min}$ until the temperature reached $350{ }^{\circ} \mathrm{C}$ and for a duration of $2 \mathrm{~h}$. After that, the powder was left to cool at room temperature, and then $50 \mathrm{~mL}$ of deionized water and $18 \mathrm{~g}$ of potassium hydroxide were added and mixed for half an hour, after which the mixture was dried for $2.5 \mathrm{~h}$ at a temperature of $80^{\circ} \mathrm{C}$. The mixture containing the straw was then placed into a tube furnace for heating for one hour at a rate of $15{ }^{\circ} \mathrm{C} / \mathrm{min}$ until it reached $800{ }^{\circ} \mathrm{C}$, after which the powder was cooled again at room temperature. The straw-activated carbon was finally obtained after the powder was mixed with $0.5 \mathrm{~L}$ of $5 \%$ hydrochloric acid for half an hour and then washed and dried. The obtained yield of straw-activated carbon that was recorded by Xiong et al. reached 93\% [23].

Table 1. Comparison of major active groups that have been used to modify activated carbons applied for arsenic removal.

\begin{tabular}{cccc}
\hline Adsorbents & Active Groups & Form & References \\
\hline Fe-Mn-Sac & $\begin{array}{c}\text { Manganese dioxide and } \\
\text { iron hydroxide }\end{array}$ & As (III) & [23] \\
\hline Fe-GAC & Iron oxides & As (V) & As (V) \\
\hline $\begin{array}{c}\text { Zirocnium impregnated } \\
\text { AC (ZrAO) }\end{array}$ & Zirconium & As (V) & {$[25]$} \\
\hline $\mathrm{Fe}_{3} \mathrm{O}_{4}$-loaded activated & Iron(II,III) oxides & As (III), As (V) & {$[26]$} \\
\hline IMIGAC & Iron manganese binary \\
oxide & As (III), As (V) & {$[28]$} \\
\hline $\begin{array}{c}\text { Iron/calcium } \\
\text { impregnated AC }\end{array}$ & $\begin{array}{c}\text { Iron/calcium } \\
\text { Fe:Mn-AC }\end{array}$ & Iron-oxyhydroxides using \\
$\mathrm{Mn}^{2+}$ & As (V) & {$[29]$} \\
\hline
\end{tabular}


In order to create doped straw-activated carbon with iron hydroxide and manganese dioxide, $100 \mathrm{~mL}$ of $68 \%$ nitric acid was mixed with $5 \mathrm{~g}$ of the straw-activated carbon for $1 \mathrm{~h}$ as an oxidation step at room temperature. Then, the mixture was thoroughly washed by using distilled water to remove acid that remained in the mix. In total, $40 \mathrm{~mL}$ of hydrochloric acid at a concentration of $3 \mathrm{~mol} / \mathrm{L}$ and $150 \mathrm{~mL}$ at a concentration of $0.05 \mathrm{~mol} / \mathrm{L}$ of $\mathrm{FeCl}_{3}$ were then mixed with the previous solution at room temperature and stirred for about $22 \mathrm{~h}$; then, the whole mixture was heated for $6 \mathrm{~h}$ and $46 \mathrm{~min}$ at $100{ }^{\circ} \mathrm{C}$. After filtering and washing the prepared iron hydroxide-doped straw-activated carbon, drying was implemented at a temperature of $80{ }^{\circ} \mathrm{C}$ for a full day, and then $5 \mathrm{~g}$ was taken from the synthesized compound and mixed with $5 \mathrm{~g}$ of $\mathrm{MnSO}_{4} \cdot \mathrm{H}_{2} \mathrm{O}$, where they were stirred at a temperature of $80^{\circ} \mathrm{C}$ for $15 \mathrm{~min}$ by using $150 \mathrm{~mL}$ of distilled water with a water cooler condenser. On a separate matter, $5 \mathrm{~g}$ of $\mathrm{MnSO}_{4} \cdot \mathrm{H}_{2} \mathrm{O}$ and $10 \mathrm{~g}$ of $\mathrm{KOH}$ were mixed with $150 \mathrm{~mL}$ of deionized water and then added to the synthesized mixture, where reflux was processed for $1 \mathrm{~h}$ and $30 \mathrm{~min}$. As a final step, the product that was obtained was filtered and then washed until it became neutral and finally dried at a temperature of $50{ }^{\circ} \mathrm{C}$ in order to finalize the product and obtain a $90 \%$ yield of iron hydroxide/manganese dioxide-doped straw-activated carbon [23].

Kalaruban et al. studied the adsorption of arsenic for water purification by using granular activated carbon functionalized by iron oxides. The activated carbon was sieved into small particles ranging between 300 and $600 \mu \mathrm{m}$ in order to reduce the variety of the experiment as believed by the authors. In total, $20 \mathrm{~g}$ of the granular activated carbon was mixed in an Erlenmeyer flask with $500 \mathrm{~mL}$ of $\mathrm{FeCl}_{2}$ of a concentration of $0.1 \mathrm{M}$ while adjusting the $\mathrm{pH}$ of the solution between 4.2 and 4.5 [18]. A flat shaker was then used in order to agitate the flask for about $24 \mathrm{~h}$, at a speed of $150 \mathrm{rpm}$ and a temperature nearing $25^{\circ} \mathrm{C}$. The next step was to filter the mixture and then wash it with deionized water several times in order to remove any remaining iron salts or other precipitates residing on the external surface of the iron granular activated carbon (Fe-GAC), after which it was dried for one full day at room temperature [24].

An activated carbon impregnated by zirconium was synthesized by Velazquez-Jimenez et al. for the removal of As (V), where $10 \mathrm{~mL}$ of $\mathrm{ZrOClO}_{2} \cdot 8 \mathrm{H}_{2} \mathrm{O}$ was added to $0.1 \mathrm{~g}$ of commercial activated carbon at a $7 \%$ weight per volume concentration of zirconium ions, and the mixture was stirred for a duration of two days in order to achieve the impregnation of the activated carbon by zirconium. After being washed by deionized water, the activated carbon was then added to $10 \mathrm{~mL}$ of oxalic acid at a concentration of weight per volume of $7 \%$, and the mixture was stirred for $24 \mathrm{~h}$. The obtained compound was then subjected to filtration, after which it was rinsed and finally dried for $12 \mathrm{~h}$ at a temperature of $60{ }^{\circ} \mathrm{C}$ to finalize the synthesis of the commercial activated carbon impregnated with zirconium [25].

$\mathrm{Fe}_{3} \mathrm{O}_{4}$-loaded activated carbon was synthesized for arsenic removal by Liu et al. by using a waste biomass of sawdust. The first step was to dry the sawdust for $24 \mathrm{~h}$ at $105^{\circ} \mathrm{C}$, after which the sawdust was subjected to air cooling followed by grinding in order to reach dimensions less than or equal to 80 meshes. In total, $20 \mathrm{~mL}$ of $1 \mathrm{M} \mathrm{FeCl}_{3}$ was mixed with $20 \mathrm{~g}$ of the sample sawdust followed by adding $10 \mathrm{~mL}$ of $50 \%$ sulfuric acid. The obtained mixture was then ultrasonicated for a period of $2 \mathrm{~h}$ and then left to age for $12 \mathrm{~h}$ at a temperature of $60{ }^{\circ} \mathrm{C}$. Centrifugal separation was then used in order to obtain the residue, which was then pyrolyzed by heating at $600{ }^{\circ} \mathrm{C}$ for $115 \mathrm{~min}$ at a rate of $30 \mathrm{~mL} / \mathrm{min}$ of nitrogen. After the mixture was left to be cooled inside the furnace, the recovered product, which was now in a solid form, was washed with de-ionized water until it reached neutrality, and then it was dried for $24 \mathrm{~h}$ at $60{ }^{\circ} \mathrm{C}$ in order to obtain the final synthesized modified activated carbon [26].

There are many research works that have focused on the synthesis of adsorbents through the modification of activated carbon for arsenic removal purposes in the literature [14,22], and this solidifies the belief in the role of adsorption in general, and specifically activated carbons as potential and suitable candidates for the removal of arsenic content from wastewaters and water sources. The next section focuses on the different characteri- 
zation techniques that have been adapted for some of the reviewed activated carbons in order to get a better understanding of the main structure of activated carbons that leads towards arsenic removal.

\section{Characterizations}

Xiong et al. [23] have extensively studied the BET surface area of the different compounds that they have synthesized with straw-activated carbon as their base. These compounds were raw straw, straw-activated carbon both with and without potassium hydroxide treatment, straw-activated carbon with iron doping and finally straw-activated carbon with iron hydroxide and manganese dioxide doping. The authors found that the specific BET surface area of straw was equal to $3.98 \mathrm{~m}^{2} / \mathrm{g}$, and the largest surface area calculated was $1413.45 \mathrm{~m}^{2} / \mathrm{g}$ for Fe-SAc (iron-doped straw-activated carbon). The other observed surface areas were $130.07 \mathrm{~m}^{2} / \mathrm{g}, 1360.00 \mathrm{~m}^{2} / \mathrm{g}$ and $507.5 \mathrm{~m}^{2} / \mathrm{g}$ for straw-activated carbon without $\mathrm{KOH}$ treatment, straw-activated carbon and activated carbon doped with iron and manganese, respectively. The synthesis of an activated carbon greatly increased the surface area of straw, and further doping with iron led to an additional increase of the surface area, which is a very important parameter in adsorption, since increasing the adsorbent's surface area typically enhances the adsorption efficiency of the materials regarding arsenic removal.

The authors observed also that activated carbon with $\mathrm{KOH}$ treatment had a larger surface area than straw-activated carbon without $\mathrm{KOH}$ treatment, and this was attributed to the fact that the treatment of activated carbon with potassium hydroxide led to the creation of new pore channels within the activated carbons, which led to the increase in the total surface area. This observation is consistent with the obtained results since the activated carbon that was subjected to $\mathrm{KOH}$ treatment attained a pore volume of $0.8081 \mathrm{~cm}^{3} / \mathrm{g}$, in comparison to the pore volume of $0.2498 \mathrm{~cm}^{3} / \mathrm{g}$ for straw-activated carbon without $\mathrm{KOH}$ treatment. It was also noticed that when adding manganese dioxide $\mathrm{MnO}_{2}$ for doping into the iron-doped straw-activated carbon, the surface area experienced a sharp decrease, and this was attributed to $\mathrm{MnO}_{2}$ residing within the pore canal of the activated carbon, which adversely affected the surface area [23].

SEM analysis was conducted in order to investigate the structure of the different synthesized compounds, as shown in Figure 2. The SEM imaging of straw-activated carbon showed a large porous structure, and the SEM images that were conducted for iron-doped straw-activated carbon resulted in a similar and slightly better organized and porous structure according to Figure 2, which agrees with the calculated surface areas of both compounds. This shows that iron resided on the surface of the activated carbon and not within the pore channels. However, that is not the case for manganese and irondoped activated carbon, as SEM imaging presents an irregular shape while taking into consideration that the surface area is extremely reduced compared to that of iron-doped activated carbon; this is again attributed to the fact that manganese dioxide landed within the pore structure of the activated carbon [23].

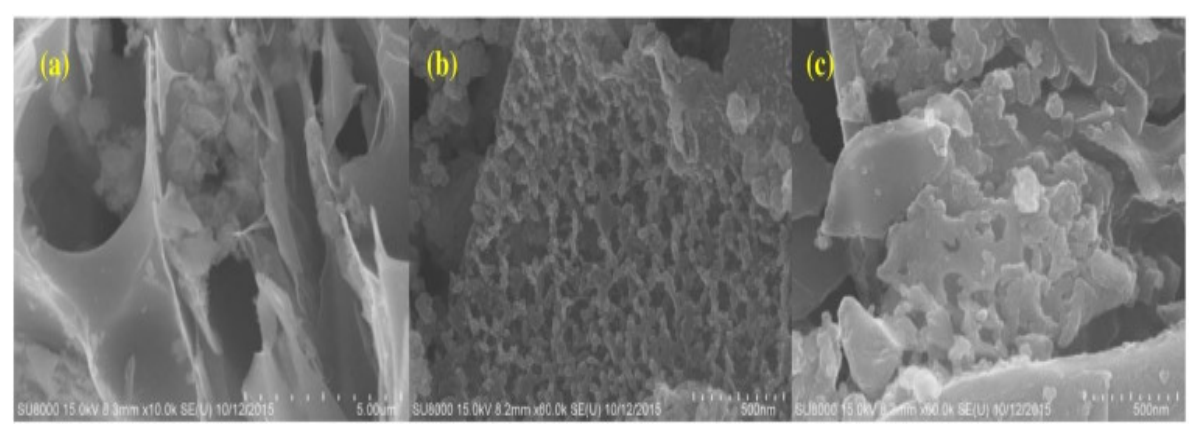

Figure 2. SEM images of: (a) straw AC, (b) Fe-SAC and (c) Fe-Mn-SAC. Reprinted from Xiong et al. [23] Copyright 2021 Elsevier. 
The authors also conducted an XRD analysis of the different synthesized activated carbons, as shown in Figure 3. The XRD analysis of the straw-activated carbon showed a peak at $22^{\circ}$, which is typical of carbon, and another peak at $36^{\circ}$, which is attributable to the Fe-O bond present in the iron-doped straw-activated carbon In contrast, a peak for $\mathrm{Mn}-\mathrm{O}$ in manganese/iron-doped straw-activated carbon was not observed in XRD analysis, suggesting that manganese dioxide had a structural change on the surface of iron-doped activated carbon [30,31]. Moreover, the typical sharp peak in manganese/irondoped straw-activated carbon is much smaller than the other peaks of the aforementioned compounds, which shows that the presence of manganese dioxide decreased the peaks of the elements that were presented previously on the surface of the activated carbon by loading on this surface [23].

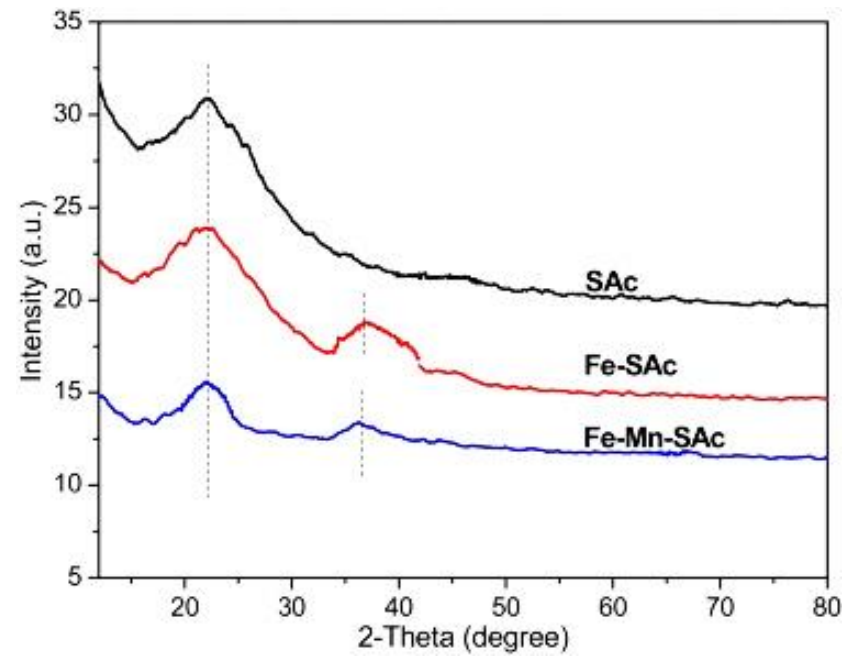

Figure 3. XRD analysis for Sac, Fe-Sac and Fe-Mn-Sac. Reprinted from Xiong et al. [23] Copyright 2021 Elsevier. (Xiong et al., 2017).

The FTIR analysis of the compounds confirmed the results from the previous characterizations. First, for straw-activated carbon, four peaks were recorded corresponding to $\mathrm{O}-\mathrm{H}$ stretching, $\mathrm{C}=\mathrm{O}$ stretching, $\mathrm{C}-\mathrm{H}$ bending and $\mathrm{O}-\mathrm{H}$ asymmetric stretching at peaks of $3438 \mathrm{~cm}^{-1}, 1556 \mathrm{~cm}^{-1}, 1415 \mathrm{~cm}^{-1}$ and $1086 \mathrm{~cm}^{-1}$ respectively. The observed peaks were nearly the same for iron-doped straw-activated carbon with the addition of a new peak at $704 \mathrm{~cm}^{-1}$ which was ascribed to Fe-O stretching [32,33]. It is noteworthy to point out that the Mn-O peaks that should be present at $720 \mathrm{~cm}^{-1}, 520 \mathrm{~cm}^{-1}$ and $450 \mathrm{~cm}^{-1}$ did not exist in the graph. This observation is in agreement with the XRD analysis, proving that a change in the structure of manganese dioxide occurred on the surface of the activated carbon [23].

Kalaruban et al. [24] measured the surface area and the pore volume of both granular activated carbon and iron-impregnated granular activated carbon. The obtained results revealed a surface area of $1124 \mathrm{~m}^{2} / \mathrm{g}$ for granular activated carbon in comparison to $876 \mathrm{~m}^{2} / \mathrm{g}$ for iron-impregnated granular AC. Moreover, the pore volume was roughly equivalent for both compounds, with a slight increment in granular activated carbon $\left(0.62\right.$ to $\left.0.6 \mathrm{~cm}^{3} / \mathrm{g}\right)$. The suppression of the surface area after the impregnation of activated carbon by iron could be attributed to the iron oxide coating, which blocked some pores of the granular activated carbon, decreasing the surface area. This has been observed also in other studies, which have also reported a decrease in the surface area of granular activated carbon after iron impregnation [34] or iron and manganese impregnation [27] and the explanation provided was based on the hypothesis that iron oxide blocked some pores of the granular activated carbon during the impregnation process. 
SEM imaging was also conducted and clearly showed the porous structure of the granular activated carbon. In addition, the images show that iron was bound on the surface of the activated carbon, most likely blocking a portion of the pores [24].

Velazquez-Jimenez et al. [25] conducted microscopy studies on zirconium functionalized activated carbon for arsenic removal in order to determine the surface morphology of the compound that was synthesized. The studies showed that adding oxalic acid led to the smallest particles sizes being reached, which ranged between 2 and $10 \mathrm{~nm}$. Moreover, SEM showed an irregular shape of the activated carbon due to complexations of zirconiumoxalate that covered the largest part of the activated carbon. Peaks of zirconium while adding oxalic acid have been also observed in XRD analysis at different shapes, which supports the successful addition of zirconium into the surface of the activated carbon [25].

Morphological studies were conducted by Liu and co-authors [26] to characterize $\mathrm{Fe}_{3} \mathrm{O}_{4}$ loaded activated carbon and activated carbon impregnated with sulfuric acid. The observed SEM images showed that both materials have a wide variety of pores with different shapes and sizes, and this could most likely be attributed to the treatment with sulfuric acid. Nevertheless, there was a difference observed on the surface of both compounds as the $\mathrm{Fe}_{3} \mathrm{O}_{4}$ loaded activated carbon had a more irregular and coarser surface in comparison to the smoother surface of activated carbon treated only with sulfuric acid, and this is due to the deposition of $\mathrm{Fe}_{3} \mathrm{O}_{4}$ particles on the surface of the activated carbon.

The FTIR analysis (Figure 4) showed the similar shapes of both compounds with some logical differences. For instance, a peak ranging from $1900 \mathrm{~cm}^{-1}$ to $1500 \mathrm{~cm}^{-1}$ was observed for both compounds, which could be attributed to carbon double bonding [35]. However, an adsorption band at around $586 \mathrm{~cm}^{-1}$ was observed for $\mathrm{Fe}_{3} \mathrm{O}_{4}$ loaded activated carbon and attributed to the torsional vibration of $\mathrm{Fe}_{3} \mathrm{O}_{4}$ in octahedral sites and Fe-O bonds in tetrahedral sites [36]. The surface area and pore volume of the $\mathrm{Fe}_{3} \mathrm{O}_{4}$ loaded activated carbon were $349 \mathrm{~m}^{2} / \mathrm{g}$ and $0.20 \mathrm{~cm}^{3} / \mathrm{g}$, respectively, which are less than the values obtained for the activated carbon treated only with sulfuric acid $\left(572 \mathrm{~m}^{2} / \mathrm{g}\right.$ and $0.28 \mathrm{~cm}^{3} / \mathrm{g}$, respectively) [26], showing that the loading of $\mathrm{Fe}_{3} \mathrm{O}_{4}$ particles into the activated carbon led to a decrease in its surface area, possibly due to the blockage of some pores during the binding process. Despite the decrease in surface area due to the addition of $\mathrm{Fe}_{3} \mathrm{O}_{4}$ particles, the authors still synthesized an activated carbon that has a comparable surface area to other studies that have focused also on synthesizing carbons from waste biomass $[37,38]$.

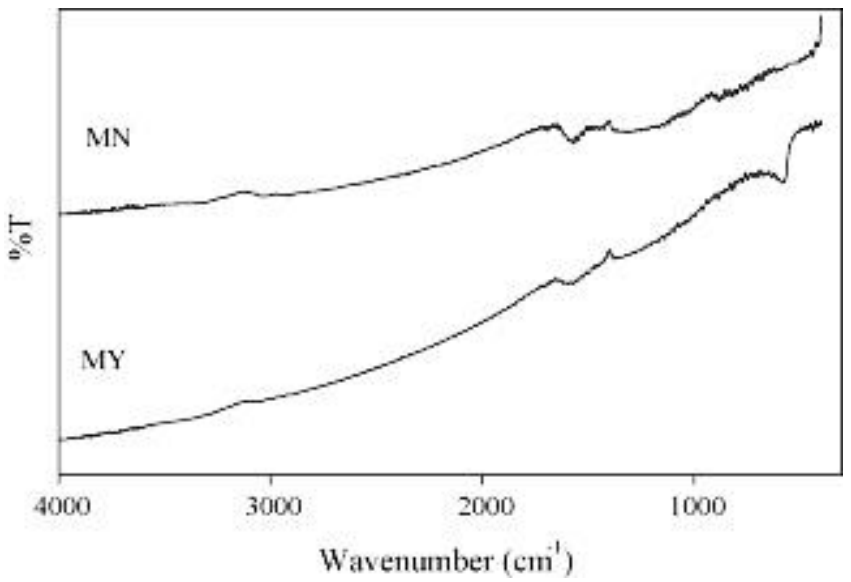

Figure 4. FTIR spectra of $\mathrm{Fe}_{3} \mathrm{O}_{4}$ loaded activated carbon (MY) and activated carbon treated with sulfuric acid (MN). Reprinted from Liu et al. [26] Copyright 2021 Elsevier.

Hashim et al. [39] investigated the adsorption of As(V) by activated carbon using a rotating packed bed. The authors implemented FTIR analysis, SEM and BET in order to conduct the characterization of their acquired activated carbon. By using the adsorption/desorption isotherms and the BET equation, the investigators obtained a BET surface 
area of $583 \mathrm{~m}^{2} / \mathrm{g}$ for the activated carbon. The results shown by the obtained isotherms showed that the pore types fitting the used activated carbon can be classified as micropores and mesopores. Those results were also proven by the pore size distribution, which also showed that the majority of the structure of the activated carbon was either mesoporous or microporous with an average pore size of $22 \AA$. SEM images also supported the obtained results, as the pictures obtained in the process showed that the activated carbon had a rough and porous surface.

The data provided by the FTIR analysis showed the existence of $\mathrm{O}-\mathrm{H}$ stretching, which could be attributed to alcohol or phenol groups due to the peak observed between $3500 \mathrm{~cm}^{-1}$ and $3200 \mathrm{~cm}^{-1}$. The results suggest also that alkanes, which are represented by $\mathrm{C}-\mathrm{H}$ stretching, are not present in the activated carbon since the peak observed between $3000 \mathrm{~cm}^{-1}$ and $2850 \mathrm{~cm}^{-1}$ was of low intensity. The authors observed multiple peaks ranging between $1580 \mathrm{~cm}^{-1}$ and $1650 \mathrm{~cm}^{-1}$, indicating the presence of $C-C$ stretching for aromatic rings and carboxyl groups, which are usually indicated by $\mathrm{C}=\mathrm{O}$ and $\mathrm{C}-\mathrm{O}$ stretching [40]. In addition, another peak corresponding to C-O stretching and indicating ester, alcohol and carboxylic acid groups was observed at a peak in the range of $1300-1000 \mathrm{~cm}^{-1}$ [39].

Three different activated carbons-GL100, GL 200 and XHIT-were evaluated and characterized for the removal of arsenic by Gong et al. [28]. According to nitrogen adsorption/desorption isotherms and at a relative pressure less than 0.2 , the nitrogen uptake for XHIT and GL200 was larger than that of GL100, which could suggest that the micropores developed better in these two types of activated carbons. When $\mathrm{P} / \mathrm{P}_{0}$ was slightly above 0.4 , a typical type IV isotherm with an $\mathrm{H}_{3}$ hysteresis loop was observed for all of the investigated activated carbons, which is in fact connected to capillary condensation [41]. The presence of a mesoporous structure was verified when the nitrogen uptake greatly increased when the relative pressure was larger than 0.8 [42]. The average pore sizes obtained for XHIT, GL200 and GL100 were 37.904, 34.95 and $38.232 \AA$, respectively, proving the mesoporous structure of the investigated activated carbons. The mesopore volumes of XHIT $\left(0.5669 \mathrm{~cm}^{3} / \mathrm{g}\right)$ and GL200 $\left(0.5255 \mathrm{~cm}^{3} / \mathrm{g}\right)$ were higher than that of GL100 $\left(0.438 \mathrm{~cm}^{3} / \mathrm{g}\right)$ at an average pore diameter ranging between 50 and $500 \AA$. However, the opposite was observed when an average pore diameter ranging between 20 and $50 \AA$ was taken into consideration since the mesopores volumes of both GL200 $\left(0.2433 \mathrm{~cm}^{3} / \mathrm{g}\right)$ and XHIT $\left(0.2405 \mathrm{~cm}^{3} / \mathrm{g}\right)$ were much smaller than GL $100\left(0.5668 \mathrm{~cm}^{3} / \mathrm{g}\right)$, indicating that GL100 has a smaller distribution of mesopores in comparison to GL200 and XHIT [28].

The surface chemistry of the activated carbons was also determined after the impregnation with iron/calcium. Boehm's titration indicated that both the carboxyl group and the basic group were better developed in the modified GL100 and GL200 than XHIT. The carboxyl groups on the surfaces of GL200 and GL100 were $8.21 \mathrm{mmol} / \mathrm{g}$ and $8.32 \mathrm{mmol} / \mathrm{g}$, while the basic groups were 8.12 and $8.23 \mathrm{mmol} / \mathrm{g}$, respectively. In addition, GL100 and GL200 had a higher ash content because of the modification of the surface via iron and calcium in-situ impregnation [43]. In total, $6.0555 \%$ and $6.562 \%$ of the ash contents were attributed to the in-situ impregnation by calcium and iron for GL200 and GL100, respectively [28].

The authors also conducted an FTIR analysis, which showed that $\mathrm{O}-\mathrm{H}$ stretching for GL100 was present in the area ranging between $4000 \mathrm{~cm}^{-1}$ and $2500 \mathrm{~cm}^{-1}$, which included hydroxyl groups at $3778 \mathrm{~cm}^{-1}$ and alcohol or phenol groups (O-H stretching) at $3701 \mathrm{~cm}^{-1}$. C-H stretching corresponding to either alkanes or aliphatic groups was observed at $2921 \mathrm{~cm}^{-1}$. Moreover, carboxyl groups represented by $\mathrm{C}-\mathrm{O}$ or $\mathrm{C}=\mathrm{O}$ stretching were present at $1591 \mathrm{~cm}^{-1}$, while $-\mathrm{NH}_{2}$ vibrations were observed at $1640 \mathrm{~cm}^{-1}$. The presence of ester, carboxylic acid or alcohol represented by $\mathrm{C}-\mathrm{O}$ and $\mathrm{C}-\mathrm{OH}$ stretching was observed in the fingerprint area at $1275 \mathrm{~cm}^{-1}$; furthermore, Si-O and Fe-O stretching were observed at 1082 and $626 \mathrm{~cm}^{-1}$, respectively [44]. GL200 showed $3179 \mathrm{~cm}^{-1}$ of O-H stretching for either alcohol or phenol groups or carboxyl groups represented by $\mathrm{C}=\mathrm{O}$ or C-O stretching at $1591 \mathrm{~cm}^{-1}$. Furthermore, GL200 contained an aromatic ring (Ca-O 
stretching) at $466 \mathrm{~cm}^{-1}$. The FTIR results for XHIT indicated the presence of hydroxyl groups via $\mathrm{O}-\mathrm{H}$ stretching at $3472 \mathrm{~cm} \mathrm{~cm}^{-1}$, partially N-H stretching, $\mathrm{O}-\mathrm{H}$ groups and $\mathrm{H}$ bonds at $3415 \mathrm{~cm}^{-1}$ alongside $\mathrm{C}=\mathrm{O}$ stretching at 1616 and $1591 \mathrm{~cm}^{-1}$ [28].

Nieto-Delgado et al. [29] investigated the modification of commercial activated carbon with iron and manganese for the removal of arsenic from water. Generally, pristine F400 is characterized by having a wide pore size distribution ranging normally from ultramicropores to small mesopores. By applying hydrothermal treatment and without the presence of manganese or iron ions, the authors noticed that the surface area of the activated carbon increased from 776 to $891 \mathrm{~m}^{2} / \mathrm{g}$, probably due to oxidation of labile carbon fractions and some inorganics that dissolved [37]. On the other hand, the surface area of the modified activated carbon with iron/manganese decreased between 3 and $40 \mathrm{~m}^{2} / \mathrm{g}$ even though a high amount of iron was deposited into the surface. In terms of the pore fraction, the ultra-micropores experienced the majority of this decrease ( $15 \%$ of the total pore volume), which indicates that some smaller iron particles were able to penetrate the pores of the activated carbon.

The crystalline structure of the modified activated carbon was evaluated by XRD. The results showed a poor crystalline structure as a wide band with the values of $44^{\circ}$ and $26^{\circ}$ at $2 \theta$ for all carbons. For all the tested samples, sharp peaks representing hematite, goethite and graphite were observed. Goethite is an element present usually in pristine F400 activated carbon, and after the activated carbon was modified in the presence of iron and manganese, the intensity of the goethite peak sharply increased and the hematite peak appeared [37].

Even though the XRD for both the iron modified activated carbon (Fe-F400) and the modified activated carbon with both iron and manganese was similar, the morphological structure according to SEM showed some differences. For instance, the average particle size was $40 \mathrm{~nm}$ for Fe-F400 widely distributed on the surface of the activated carbon, while the structure of Fe:Mn-activated carbon showed the presence of a quasi-sphere, which normally has an average diameter of $500 \mathrm{~nm}$ and is formed by nanorods that have an average length of $20 \mathrm{~nm}$. Generally, the authors observed that the largest surface area of the activated carbon was covered by iron, and they relate this high deposition of iron onto the surface area of the activated carbon with the high adsorption capacity that was obtained during the experiment (5 $\mathrm{mg}$ As/g carbon) [29].

\section{Adsorption Evaluation}

\subsection{Effect of $p H$}

When dealing with arsenic removal by adsorption, the $\mathrm{pH}$ of the aqueous solution has a major influence on the structure of the adsorbent and the way in which arsenic compounds are distributed within the solution. For example, the removal of arsenic using straw-activated carbon was practically unaffected by $\mathrm{pH}$ variation, suggesting that the straw-activated carbon did not possess functional groups that could react with arsenic [23]. When the activated carbon was doped with iron hydroxide, the best removal efficiency of arsenite was $55 \%$ and was achieved at a pH equal to 9 because of the adsorption of $\mathrm{H}_{2} \mathrm{AsO}_{3}{ }^{-}$ions by hydroxide. In the case of manganese-doped straw-activated carbon, the manganese oxide oxidized arsenite into arsenate, and the resulting removal efficiency of arsenite dropped to $47 \%$ at a $\mathrm{pH}$ of 2 .

For the straw-activated carbon that was doped in both manganese dioxide and iron hydroxide, the results were similar to those observed in the manganese-doped activated carbon as the adsorption efficiency of arsenite increased with the decrease of the $\mathrm{pH}$ of the solution, reaching an optimum adsorption efficiency of $85 \%$ at a $\mathrm{pH}$ equal to 3 . However, when the $\mathrm{pH}$ reached a value of 2 , a sharp decrease in the adsorption of arsenic was observed, and this was due to the $\mathrm{pk}_{\mathrm{a}}$ characteristics of arsenic. It is noteworthy that, at a $\mathrm{pH}$ equal to 3, arsenite is present in the solution as $\mathrm{H}_{3} \mathrm{AsO}_{3}$, while arsenate is present as the anion $\mathrm{H}_{2} \mathrm{AsO}_{4}{ }^{-}$. Therefore, the major driving force of arsenate removal at this specific acidic $\mathrm{pH}$ is the electrostatic bonding between the arsenate anion and the positively charged 
ions residing on the surface of the iron/manganese-doped straw-activated carbon [23]; for a similar reason, optimized $\mathrm{As}(\mathrm{III})$ removal was observed at higher $\mathrm{pH}$ values, at which As(III) starts to dissociate.

When testing the effect of $\mathrm{pH}$ in arsenic removal by granular activated carbon, Kalaruban et al. [24] noticed that the increase in $\mathrm{pH}$ decreased the zeta potential of both granular activated carbon and the iron-modified granular activated carbon as the zeta potential of granular activated carbon in the presence of arsenic decreased from a value of around $-5 \mathrm{mV}$ to $-40 \mathrm{mV}$ approximately for an ascending $\mathrm{pH}$ increasing from 3 until a $\mathrm{pH}$ of approximately 7 was reached. Similarly, and for nearly the same range of $\mathrm{pH}$, the zeta potential for modified granular activated carbon in the presence of arsenic also decreased from $5 \mathrm{mV}$ until it reached a level of around $-15 \mathrm{mV}$. This basically means that an increase in the $\mathrm{pH}$ of the solution will in fact increase the negatively charged groups on the surface of activated carbon. This in turn decreases the adsorption of the arsenic anions into the surface, thus leading to a decrease in the overall adsorption due to the repulsion of these anions from the surfaces if the electrostatic attraction were to be the major force driving the mechanism. After modification with iron, the zeta potential of the iron-modified granular activated carbon increased to a positive value of 8 ; besides, the zero point of charge rose from 3.2 to 8 . This means that the introduction of iron to the activated carbon allowed the enhancement of positive charges on the surface of the modified activated carbon, which led to an increase in adsorption as iron-modified AC showed a better adsorption than granular activated carbon.

It was also observed that when exceeding a $\mathrm{pH}$ level of 6 , the adsorption for both investigated compounds decreased, and this was due to the increasing positive charges on both the surface of the adsorbent and within the solution; moreover, this increase in the $\mathrm{pH}$ naturally increased hydroxide ions in the solution, creating a competition between arsenic and hydroxide ions for adsorption on the surface of the activated carbon and thus decreasing the adsorption capacity $[25,34]$. The final $\mathrm{pH}$ recorded after the adsorption process was concluded was always lower that the initial starting $\mathrm{pH}$ for initial $\mathrm{pH}$ levels values above 6 , whereas starting the experiment at $\mathrm{pH}$ value below 6 did not lead to any major change between the final and the starting $\mathrm{pH}$ value. This trend was attributed to the adsorbent releasing $\mathrm{H}^{+}$protons during the adsorption of arsenic, alongside the adsorption of hydroxide ions into the surface of the activated carbon with increasing $\mathrm{pH}[24,34]$.

Velazquez-Jimenez et al. [25] observed in their investigation of zirconium functionalized activated carbon that the adsorption of arsenic increased in weak acidic medium specifically in a $\mathrm{pH}$ ranging between 3 and 7; in addition, a 97\% decrease in adsorption was obtained when the $\mathrm{pH}$ of the solution increased from 8 to 11 . The maximum adsorption capacity that was obtained in the acidic conditions was $3.5 \mathrm{mg} / \mathrm{g}$. The increase in adsorption in this study was due to the interaction between the positively charged zirconium-oxalate complex and the arsenic anions present in the solution. Besides, the increase in $\mathrm{pH}$ led to the release of hydroxide ions in the solution, which wpiöd definitely compete with the arsenate ions for the attraction on the surface of the activated carbon, and this phenomena created a barrier or a restriction of negative charges that prevented the adsorption of arsenic into the surface of the adsorbent, eventually leading to a decrease in arsenic uptake [25].

In order to find the optimum $\mathrm{pH}$ value, Liu et al. [26] conducted experiments at various $\mathrm{pH}$ values and examined the removal of $\mathrm{As}(\mathrm{V})$ by $\mathrm{Fe}_{3} \mathrm{O}_{4}$ loaded particles on activated carbon from waste biomass. Parameters such as the arsenate concentration and contact time were set at $40 \mathrm{mg} / \mathrm{L}$ and $6 \mathrm{~h}$, and the effect of $\mathrm{pH}$ is shown in Figure 5. It was noticed in this experiment that the adsorption increased slightly when the $\mathrm{pH}$ increased until it reached a maximum value at a $\mathrm{pH}$ of 8 , after which it started decreasing again; when the $\mathrm{pH}$ attained a value of 12 , the adsorption was almost non-existent according to Figure 5. The adsorption of arsenate into the synthesized activated carbon could be attributed to two main reasons, which are the chemical reaction with $\mathrm{Fe}_{3} \mathrm{O}_{4}$ or affinity adsorption [45]. Taking into consideration the effect of $\mathrm{pH}$, the authors concluded that the chemical reaction was the main driving force for adsorption, and the increase in $\mathrm{pH}$ led to 
an increase in the negative charges on the surface, which in turn promoted the repulsion of arsenate ions from the surface of the adsorbent and eventually decreased its adsorption with increasing $\mathrm{pH}[26]$.

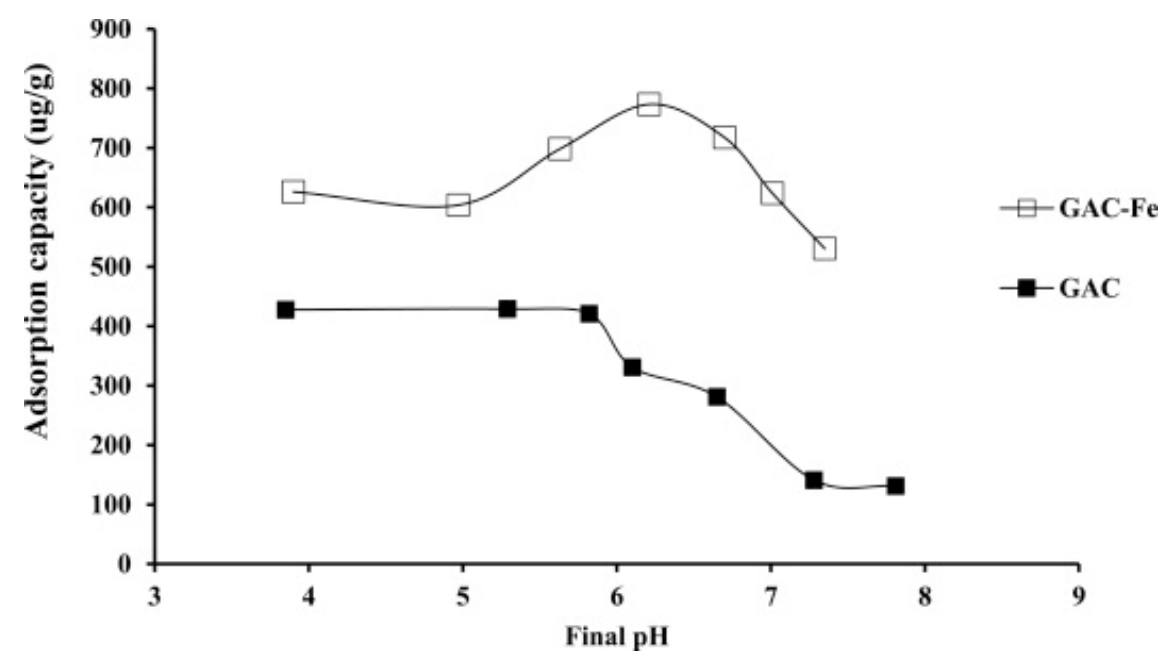

Figure 5. Effect of $\mathrm{pH}$ on arsenic adsorption on both GAC and iron-impregnated GAC. Reprinted from Kalaruban et al. [24] Copyright 2021 Elsevier.

\subsection{Kinetic Studies}

The characterization of any adsorbent is particularly important to understand the morphological properties of the compound and its ability to be used for the purpose of adsorption. It is also important to perform an adsorption evaluation on the removal of a compound in order to understand the driving mechanism of the adsorption process, therefore allowing its modification, which in turn improves the adsorption efficiency. Table 2 summarizes most of the findings from the adsorption evaluation that was conducted on some of the activated carbons used for arsenic removal.

Xiong et al. [23] studied the kinetics of their process in order to understand better the mechanism that governs the adsorption of arsenic into iron hydroxide/manganese dioxide activated carbon. For this matter, the Elovich equation, intra-particle diffusion and both pseudo-first-order and pseudo-second-order were investigated [50,51]. It was found that the pseudo-second-order kinetic model fitted the adsorption mechanism of arsenite into manganese and iron-doped straw-activated carbon best with a linear regression of $\mathrm{R}^{2}=1$. The adsorption for pseudo-second-order in this experiment increased with increasing temperature, and around $78 \%$ of the initial concentration of arsenic was removed during the first hour, with equilibrium reached at $8 \mathrm{~h}$. This slow adsorption stage that was observed after one hour could be explained by the fact that adsorption occurs by the adsorption of arsenic first of all into the surface of the modified straw-activated carbon, followed by an intra-particle diffusion within the pores between the arsenite and the carbon [23].

Kalaruban et al. [24] noticed that the adsorption was rapid for both iron-impregnated granular activated carbon and activated carbon, as it only took $30 \mathrm{~min}$ to reach $50 \%$ of the adsorption capacity and between 4 and $5 \mathrm{~h}$ to reach $90 \%$ of the adsorption capacity. The data obtained fitted both models perfectly for both investigated adsorbents; however, the maximum adsorption capacity for the granular activated carbon fitted the predicted maximum adsorption capacity of the pseudo-first-order model better, and the maximum adsorption capacity that was predicted by the pseudo-second-order model agreed with the adsorption capacity that was obtained for iron-impregnated granular activated carbon. This means that the adsorption of arsenic into granular activated carbon was of the pseudofirst-order, which indicates physical adsorption, and chemical adsorption was implied for 
the case of the removal of arsenic by iron-impregnated granular activated carbon since it fitted the pseudo-second-order model [24].

Table 2. Kinetics model, adsorption isotherm and maximum Langmuir adsorption capacity of some adsorbents based on AC for arsenic removal (WM corresponds to the Weber-Morris equation model).

\begin{tabular}{|c|c|c|c|c|c|}
\hline Adsorbents & Form & Kinetic Model & Qm (mg/g) & Isotherm Model & References \\
\hline Fe-Mn-Sac & As (III) & ps2 & 75.82 & Langmuir & [23] \\
\hline $\begin{array}{l}\text { Commercial activated carbon } \\
\text { F400 }\end{array}$ & As (V) & ps1 & 2.72 & Langmuir & [25] \\
\hline $\begin{array}{l}\text { Zirocnium impregnated AC } \\
\text { (ZrAO) }\end{array}$ & As (V) & ps2 & 3.9 & Langmuir & [25] \\
\hline $\begin{array}{c}\text { Granular activated carbon } \\
\text { (GAC) }\end{array}$ & As $(\mathrm{V})$ & ps1 & 1.01 & Freundlich & [24] \\
\hline Fe-GAC & As $(V)$ & ps2 & 1.43 & Freundlich & [24] \\
\hline $\begin{array}{c}\mathrm{Fe}_{3} \mathrm{O}_{4} \text { loaded activated carbon } \\
(\mathrm{MY})\end{array}$ & As $(V)$ & ps2 & 204.2 & Freundlich & [26] \\
\hline $\begin{array}{c}\text { Iron/calcium-impregnated AC } \\
\text { (GL100 }\end{array}$ & As (III), As (V) & ps2 & $2.985 / 3.385$ & Langmuir & [28] \\
\hline $\begin{array}{l}\text { Iron/calcium-impregnated AC } \\
\text { (GL200) }\end{array}$ & As (III), As (V) & ps2 & $2.516 / 2.807$ & Langmuir & [28] \\
\hline $\begin{array}{c}\text { Regular mesoporous carbon } \\
\text { (XHIT) }\end{array}$ & As (III), As (V) & ps2 & $1.936 / 2.013$ & Langmuir & [28] \\
\hline Pristine activated carbon (F-400) & As $(V)$ & ps2 & 1.99 & Langmuir & [29] \\
\hline Mn-F400 & As (V) & WM & 1.49 & Langmuir & [29] \\
\hline Fe-F400 & As (V) & ps2 & 3.55 & Langmuir & [29] \\
\hline Fe:Mn- 2mol/L & As (V) & ps2 & 4.96 & Langmuir & [29] \\
\hline$\delta-\mathrm{MnO}_{2}$ loaded $\mathrm{AC}$ & As (III), As (V) & ps2 & $13.3 / 12.56$ & Langmuir & [46] \\
\hline Limonia acidissima shell AC & As (III) & ps2 & 68.77 & Langmuir & [47] \\
\hline Tamarix leaves AC & As (III) & ps2 & 37.313 & Freundlich & [48] \\
\hline Iron oxide clay-AC & As (V) & ps1 & 5 & Langmuir & [49] \\
\hline F400-SM & As $(\mathrm{V})$ & ps2 & 1.01 & Langmuir & [19] \\
\hline CAZ-SM & As (V) & ps2 & 0.25 & Langmuir & [19] \\
\hline CAP-SM & As (V) & ps2 & 0.167 & Langmuir & [19] \\
\hline F400-M & As (V) & ps2 & 1.25 & Langmuir & [19] \\
\hline CAZ-M & As $(\mathrm{V})$ & ps2 & 0.526 & Langmuir & [19] \\
\hline CAP-M & As (V) & ps2 & 0.37 & Langmuir & [19] \\
\hline
\end{tabular}

The Weber and Morris equation was also plotted in order to determine if diffusion played a role in the adsorption rate, and the results showed that the adsorption is controlled by intra-particle diffusion. For granular activated carbon, the first stage showed a rapid rate constant followed by a slower one, and those stages could be attributed to the diffusion of As into the mesopores of the activated carbon in the first step followed by the intraparticle diffusion of arsenic within the activated carbon from the mesopores into the micropores. The authors also found that the rate constants regarding iron-impregnated granular activated carbon were much slower than those of granular activated carbon, and this is due to the blockage of some pores by iron impregnation [24].

Velazquez-Jimenez et al. also investigated the kinetic studies in order to evaluate the mechanism of adsorption for both commercial activated carbon and zirconiumimpregnated activated carbon. The obtained kinetic model graphs are shown in Figure 6. According to the figure, $50 \%$ of arsenic content was removed in the first $40 \mathrm{~min}$ by zirconium-impregnated activated carbon, which also led to a decrease in the $\mathrm{pH}$ from 7 to 6.75 , which remained intact for the remainder of the experiment. This result is probably due to the release of $\mathrm{H}^{+}$protons by the activated carbon surface that was not occupied by the zirconium. The linear regressions that were obtained from the kinetic models fitted the experimental data for both adsorbents; however, the $p$ value indicated that the pseudo-first-order model best fitted the commercial activated carbon adsorption, while the adsorption mechanism of the zirconium-impregnated activated carbon was best fitted by 
the pseudo-second-order model, which indicates-according to the authors-a change in porosity and a strong adsorption of arsenate in the zirconium particles [25].
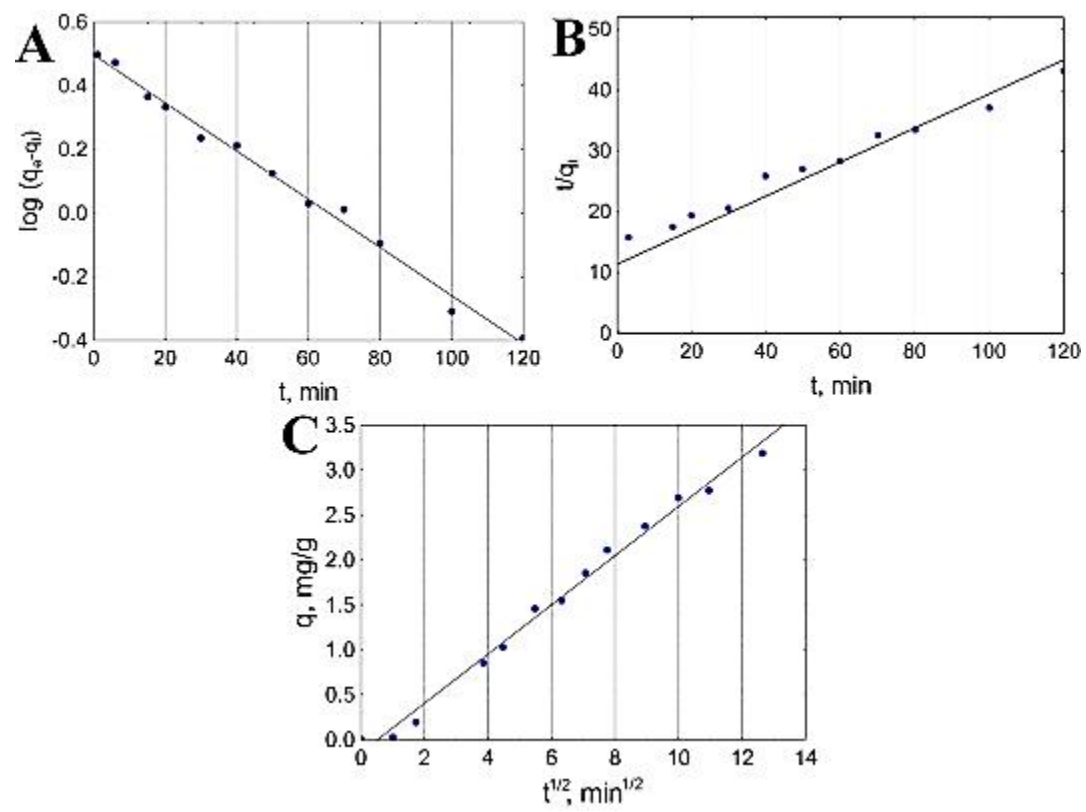

Figure 6. Adsorption kinetic modeling of As into zirconium-modified activated carbon: (A) pseudofirst-order, (B) pseudo-second-order and (C) intraparticle diffusion. Reprinted from VelazquezJimenez et al. [25] Copyright 2021 Elsevier.

Since the two models do not describe the physical mass transfer process, the authors implemented the intrapartical diffusion model, and the results showed a similar behavior for both tested adsorbents, starting with a first stage described as the diffusion of the arsenic into the surface of the adsorbent followed by the intraparticle diffusion of arsenic within the pores of the activated carbon. The authors also showed that he $\mathrm{C}$ constant of the intraparticle diffusion models did not reach zero in both cases, which means that the intraparticle diffusion is not the only mechanism that is driving the adsorption of arsenic into the activated carbons [25].

Liu et al. also investigated the kinetics of the adsorption of arsenate into $\mathrm{Fe}_{3} \mathrm{O}_{4}$ loaded activated carbon at a stable $\mathrm{pH}$ of 8 while varying temperature and initial concentration. The increase in the initial concentration of arsenic increased the adsorption capacity, and $95 \%$ removal of arsenic was attained in less than $6 \mathrm{~h}$. The increase in adsorption with increasing initial concentration could be possibly due to the greater contact between arsenate and the surface area of the adsorbent. In addition, after plotting the kinetic models and comparing the experimental data, the authors found that the pseudo-second-order model fitted the adsorption of arsenic into the $\mathrm{Fe}_{3} \mathrm{O}_{4}$ loaded activated carbon [26].

\subsection{Isotherms and Effect of Temperature}

The adsorption isotherm is an important step to determine the relation between adsorbates at equilibrium and their respective concentration in aqueous solution in addition to providing a better understanding of the method in which adsorption occurs [52]. Xiong et al. studied three isotherm models in their experiment-Langmuir, Freundlich and Temkin - and the results are plotted in Figure 7. The linear regression that was obtained showed that the Freundlich isotherm $\left(R^{2}=0.9027\right)$ was the least predictive model, followed by the Temkin isotherm $\left(R^{2}=0.9295\right)$, and the Langmuir isotherm model best fitted the experimental data of the adsorption process with an $\mathrm{R}^{2}$ of 0.9722 . This indicates that the adsorption of arsenic by the iron hydroxide/manganese dioxide-modified activated carbon is actually a monolayer adsorption process. In addition, the maximum adsorption capacity was $75.82 \mathrm{mg} / \mathrm{g}$ and was obtained at a $\mathrm{pH}$ of 3 [23]. The authors have tated that 
the high amount of adsorption capacity that was obtained in their experiment was due to the large surface area provided by the iron hydroxide/manganese dioxide modification of the activated carbon, and this adsorption capacity was larger than several adsorption capacities that were obtained for activated carbons modified by either iron or manganese or both in previous literature [52-59]. The authors concluded that these characteristics show that iron hydroxide/manganese dioxide-modified activated carbon is a good adsorbent for the removal of arsenic from wastewater [23].

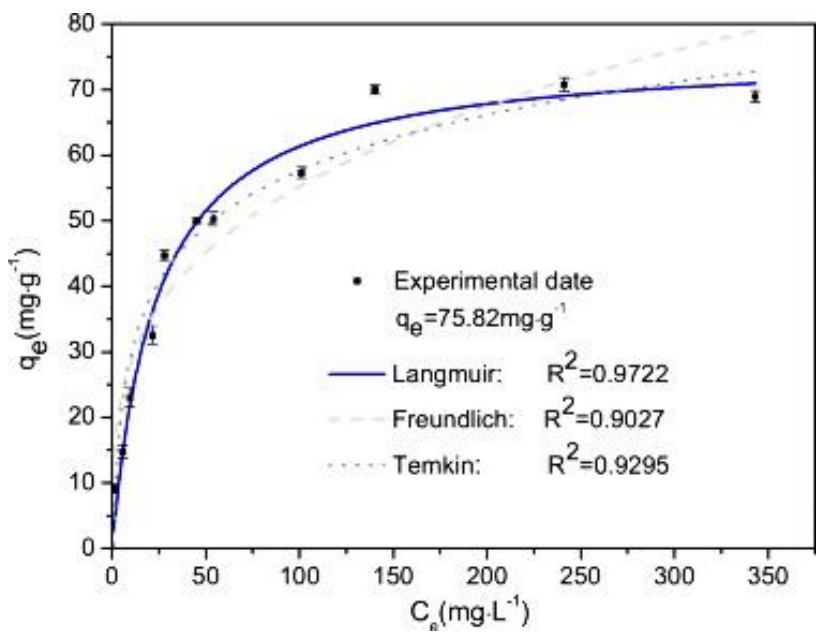

Figure 7. Adsorption isotherm of arsenic on Fe-Mn-AC. Reprinted from Xiong et al. [23] Copyright 2021 Elsevier.

Kalaruban et al. found out that both Langmuir and Freundlich models fitted their experimental data, with a slight advantage for the Freundlich isotherm which obtained $\mathrm{R}^{2}$ values for iron granular activated carbon and granular activated carbon of 0.99 and 0.94, respectively. It was also found that the Langmuir isotherm model gave satisfactory results and a good prediction for the experimental data of the granular activated carbon only because the data from the iron-modified granulated activated carbon poorly fitted the data. A possible explanation is that the granular activated carbon provided one type of adsorption, while the iron oxide deposited on the surface of the granular activated carbon provided another type [24]. Langmuir adsorption capacities were $1.43 \mathrm{mg} / \mathrm{g}$ and $1.01 \mathrm{mg} / \mathrm{g}$ for iron-modified granular activated carbon and granular activated carbon, respectively. The Freundlich parameter for the iron-modified activated carbon was higher than that for granular carbon, which indicates that the iron impregnation led to an increase in adsorption capacity. The separation factor of the Langmuir model was also calculated for both adsorbents and was found to be 0.24 and 0.53 for the granular activated carbon and the iron-modified carbon, respectively, and both values indicate that the adsorption was a favorable process [24]. Similar research works also show that modifying granular activated carbon with iron increases the adsorption of arsenic into the activated carbon $[18,60,61]$.

Velazquez-Jimenez et al. showed that the Langmuir isotherm fitted their experimental data better for both the commercial activated carbon F400 and the zirconium-modified activated carbon. In addition, the maximum adsorption capacity was higher by nearly $43 \%$ for the zirconium-modified activated carbon $(3.9 \mathrm{mg} / \mathrm{g}$ in comparison to $2.72 \mathrm{mg} / \mathrm{g}$ for F400) [25]. The zirconium content in this experiment was only around $0.77 \%$, which was enough to raise the adsorption capacity of $\mathrm{F} 400$ by $43 \%$; besides, the obtained adsorption capacity in this experiment was multiple times higher than the other adsorption capacities obtained by addition of zirconium into other materials for adsorption purposes [62,63].

The ranges of adsorption capacities obtained by Liu et al. [26] for activated carbon treated only with sulfuric acid and activated carbon loaded with $\mathrm{Fe}_{3} \mathrm{O}_{4}$ particles were found to be between 6.8 and $28 \mathrm{mg} / \mathrm{g}$ and between 12.2 and $61 \mathrm{mg} / \mathrm{g}$, respectively. The data represented in Figure 8 fitted the Freundlich model better, even though the Langmuir 
model achieved satisfactory results ( $\mathrm{R}^{2}$ values of 0.99 and 0.93 , respectively). This could explain the heterogeneous adsorption to the surface of the activated carbon. Moreover, the magnitude of the Freundlich component was found to be equal to 1.19 , which indicates that the process is favorable. The maximum adsorption capacity of arsenic into the $\mathrm{Fe}_{3} \mathrm{O}_{4}$ particle loaded activated carbon was found to be equal to $204.2 \mathrm{mg} / \mathrm{g}$ [26].

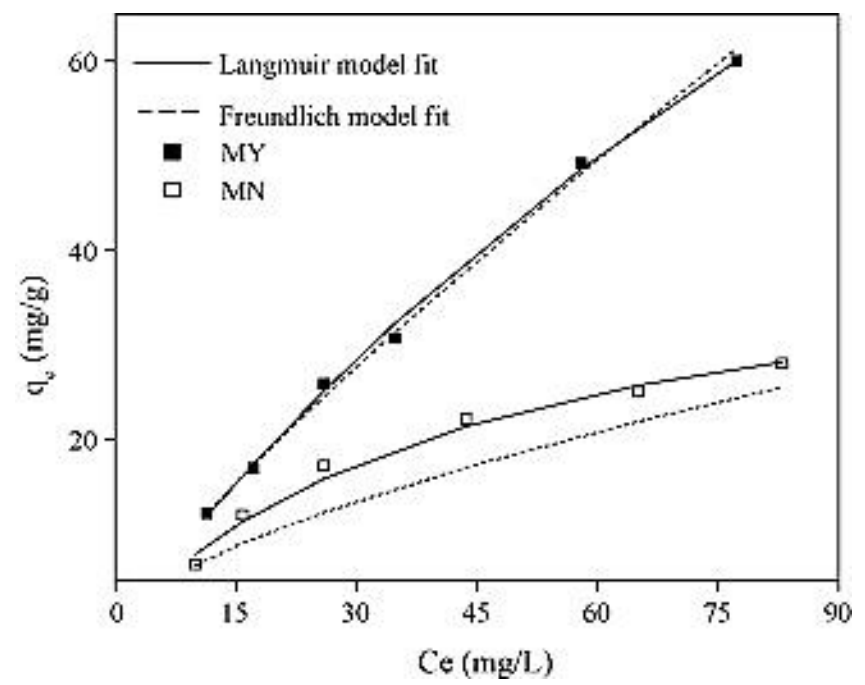

Figure 8. Adsorption isotherm of (MY) and (MN). Reprinted from Liu et al. [26] Copyright 2021 Elsevier (Liu et al., 2010).

\subsection{Effect of Temperature on Arsenic Adsorption by Activated Carbons}

Regarding the effect of temperature on the adsorption of arsenic into activated carbons, there have not been many works depicting specifically this process; however, attention to the temperature effect was still given in some papers. For example, for manganese dioxide/iron hydroxide-modified activated carbon, the adsorption capacity increased with the increase of temperature while testing with a temperature ranging between $293 \mathrm{~K}$ and $323 \mathrm{~K}$ [23]. This result is not necessary in all experiments, since Velazquez-Jimenez et al. found that the adsorption capacity of arsenate into zirconium functionalized activated carbon increased with the decrease in temperature, and the maximum adsorption capacities of arsenate at $15^{\circ} \mathrm{C}$ and $35^{\circ} \mathrm{C}$ were found to be 5.06 and $2.29 \mathrm{mg} / \mathrm{g}$, as shown in Figure 9 [25].

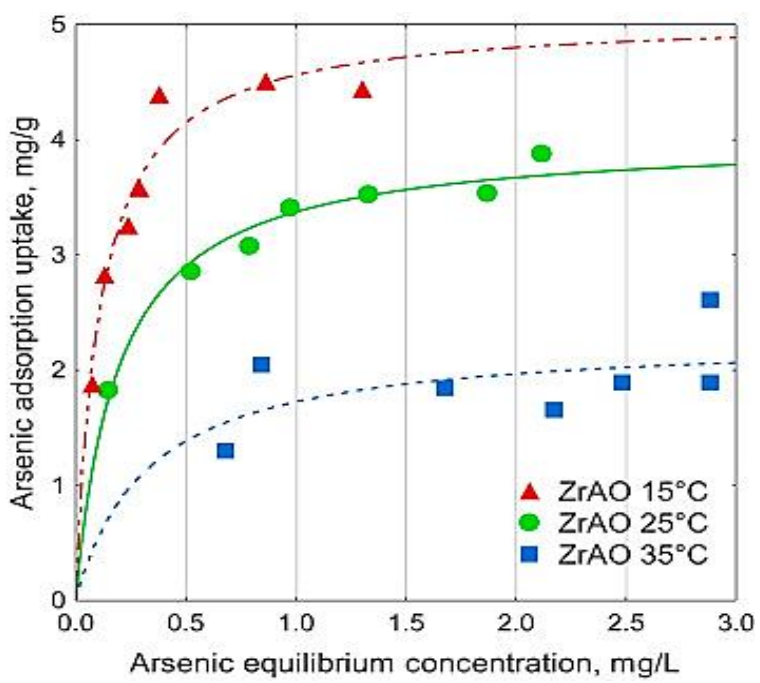

Figure 9. Effect of temperature and initial concentration on adsorption of As (V) into zirconiumactivated carbon. Reprinted from Velazquez-Jimenez et al. [56] Copyright 2021 Elsevier. 


\section{Regeneration}

Wang et al. derived an activated carbon modified by $\mathrm{MnO}_{2}$ in order to remove arsenic from water and studied its regeneration cycle. The results of the regeneration cycle are summarized and presented in Figure 10. The original adsorption capacities that were obtained were $86.7 \%$ for arsenate and $82.5 \%$ for arsenic. These values decreased after the first cycle and reached $80.8 \%$ for arsenic and $78.4 \%$ for arsenite. After three cycles using the same adsorbent, the adsorption capacities remained acceptable and slightly decreased to reach $75.5 \%$ for arsenate and $73.1 \%$ for arsenic [46].

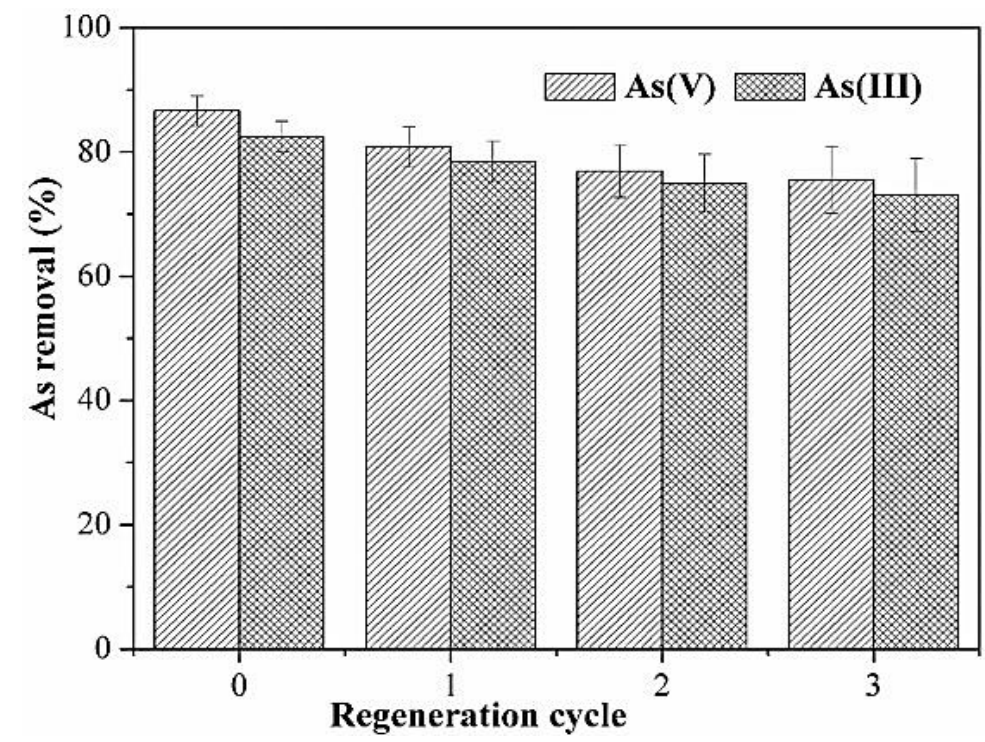

Figure 10. Regeneration of $\mathrm{MnO}_{2}$-modified activated carbon. Reprinted from Wang et al. [46] Copyright 2021 Elsevier.

Xiong et al. also studied the recyclability of their compound and conducted desorption tests by mixing the iron hydroxide/manganese dioxide-activated carbon that was loaded with arsenite with different percentages of sodium hydroxide in order to implement the desorption process. It was found that a solution of $0.05 \%$ of sodium hydroxide is enough to achieve a desorption exceeding $99 \%$ of the arsenic loaded into the activated carbon [23]. The reuse of the activated carbon was also investigated by conducting several cycles of adsorption-desorption, and it was noticed that the adsorption capacity of arsenic showed negligible changes, as seen in Table 3. This small decrease in the adsorption of arsenic could be attributed to the portion of manganese dioxide particles that turned into manganese ions during the redox process, which decreased the oxidation capability of arsenite [23].

Table 3. Regeneration cycles of Fe-Mn-Sac.

\begin{tabular}{cccccccc}
\hline & \multicolumn{3}{c}{ As (III) } & \multicolumn{3}{c}{ As (V) } \\
\cline { 2 - 7 } & Cycle 1 & Cycle 2 & Cycle 3 & Cycle 1 & Cycle 2 & Cycle 3 \\
\hline Initial solution (mg/L) & 14.46 & 19.6 & 180.76 & 0.44 & 0.39 & 0.24 \\
Adsorption rate (\%) & 0.13 & 1.39 & 1.75 & 16.55 & 13.55 & 12.67 \\
Recovery (\%) & 85 & 75 & 73 & - & - & - \\
\hline
\end{tabular}

Gong et al. produced iron/calcium-impregnated activated carbons (GL100, GL200 and XHIT) for the removal of arsenate and arsenite through adsorption and gave proper attention to the desorption and reusability of the compounds for eight cycles [28]. The adsorption capacity of arsenite into GL100 decreased from 2.985 to $2.836 \mathrm{mg} / \mathrm{g}$ after three cycles; then, it decreased slightly in the next three cycles and finally decreased to a value of $1.672 \mathrm{mg} / \mathrm{g}$ at the eighth cycle with a $44 \%$ total decrease. This percentage was $48.13 \%$ when 
the reusability of GL200 for the adsorption of arsenite was tested, as the adsorption capacity was reduced to $1.308 \mathrm{mg} / \mathrm{g}$ after the eighth cycle. The highest percentage of reduction for arsenite adsorption was reported for XHIT at a value of $64.98 \%$, as the adsorption capacity after the eighth cycle was only equal to $0.679 \mathrm{mg} / \mathrm{g}$. Regarding arsenate, both adsorption capacities for the GL100 and GL 200 increased after the first two cycles but then decreased again all the way to the final eighth cycle, and the appropriate adsorption capacities for XHIT, GL200 and GL100 were 1.046, 1.74 and $2.437 \mathrm{mg} / \mathrm{g}$ [28], which shows that the synthesized compounds had acceptable results in term of reusability.

\section{Conclusions and Perspectives}

The pollution of waters and wastewaters with arsenic is a global problem due to the detrimental consequences of large concentrations of arsenic in waters or wastewaters on both human health and the environment. Many studies have focused on the use of adsorption as a technique for the removal of arsenic from water streams due to its many advantages such as ease of operation and low cost. Among the several materials that have been investigated as potential adsorbents, in the present review article, we have focused on the use of activated carbons, which have recently been the focus of extensive research due to their adsorptive characteristics, which include porosity and a large surface area.

Different syntheses have been suggested in recent years to improve the morphological structure of activated carbons for the adsorption of arsenic into the surface of the adsorbent; among the most famous suggestions is the introduction of-or impregnation through the surface modification of the activated carbon with-some compounds such as iron hydroxide or manganese dioxide or even a combination of some compounds. The role of these modifications is mainly to increase the surface area of the activated carbon, which leads to the increase of adsorption capacity. In the adsorption mechanism, it is clear that $\mathrm{pH}$ plays a major role in the attraction of arsenic into the surface of the activated carbon, and usually the adsorption capacity increases with the decrease of the $\mathrm{pH}$ as the higher the $\mathrm{pH}$, the greater the quantity of hydroxide ions within the solution, which ultimately leads to the creation of a negatively charged barrier that repels the arsenic from the surface while also taking into consideration the competition between ions for the deposition on the surface of the activated carbon.

Both pseudo-first-order and pseudo-second-order models seem to fit the different adsorption experiments; however, in most cases, an additional stop involved in the adsorption process is intraparticle diffusion. Most of the experimental data in the research that focused on the removal of arsenic from aqueous solution by using activated carbon seemed to fit both Langmuir and Freundlich isotherms; therefore, adsorption could be either monolayer or heterogeneous in type. Although there is not much information in the literature on the effect of temperature in arsenic removal, there seems to be an increase in adsorption capacity with increasing temperature, even though the opposite is sometimes correct.

While investigating the potential of a material as an adsorbent, its recyclability and reuse are mandatory for its success since cost-effective methods are always considered to be implemented; as discussed in this paper, several of the synthesized activated carbons had slight drops in the adsorption capacity for both arsenite and arsenate even after several cycles, making them suitable for reuse should the material be adopted as an adsorbent for arsenic removal.

A large number of aspects have been covered for activated carbons used as adsorbents for arsenic removal; however, there seems to be a lack of research in some areas, as most of the research works have been done on a laboratory scale, and testing has occurred in aqueous solutions usually composed of a single element, whereas the reality involves a much larger water source that has various concentrations of arsenic alongside other compounds. Therefore, more investigation regarding the affinity of activated carbon towards arsenic should be conducted, as well as conducting large-scale experiments that may simulate a water stream by using a continuous phase as an example. Unfortunately, 
the literature is limited in this area, and hence more focus should be given to simulate real conditions.

Author Contributions: Conceptualization, A.K.T., I.A.K., G.Z.K.; methodology, A.K.T., I.A.K., G.Z.K.; validation, I.A.K., G.Z.K.; formal analysis, A.K.T., E.M., D.A.G., I.A.K. and G.Z.K.; investigation, A.K.T., E.M., D.A.G., I.A.K. and G.Z.K.; resources, A A.K.T., E.M., D.A.G., I.A.K. and G.Z.K.; data curation, A.K.T., E.M. and D.A.G.; writing-original draft preparation, A.K.T., E.M. and D.A.G.; writing-review and editing, A.K.T., E.M., D.A.G., I.A.K. and G.Z.K.; visualization, A.K.T., E.M., D.A.G., I.A.K. and G.Z.K.; supervision, A.K.T., I.A.K., G.Z.K. All authors have read and agreed to the published version of the manuscript.

Funding: This research received no external funding.

Data Availability Statement: All data analyzed during this study are included in this published article.

Conflicts of Interest: The authors declare no conflict of interest.

\section{References}

1. Nations, U. World Water Development Report 2018, Nature Based Solutions for Water. Available online: http://www.unwater. org/publications/world-water-development-report-2018 (accessed on 23 January 2019).

2. Murcott, S. Arsenic Contamination in the World-An International Sourcebook; IWA Publishing: London, UK, 2012.

3. Hering, J.G.; Katsoyiannis, I.A.; Theoduloz, G.A.; Berg, M.; Hug, S.J. Arsenic Removal from Drinking Water: Experiences with Technologies and Constraints in Practice. J. Environ. Eng. 2017, 143, 03117002. [CrossRef]

4. Podgorski, J.E.; Eqani, S.A.M.A.S.; Khanam, T.; Ullah, R.; Shen, H.; Berg, M. Extensive arsenic contamination in high-pH unconfined aquifers in the Indus Valley. Sci. Adv. 2017, 3, e1700935. [CrossRef] [PubMed]

5. Katsoyiannis, I.A.; Mitrakas, M.; Zouboulis, A.I. Arsenic occurrence in Europe: Emphasis in Greece and description of the applied full-scale treatment plants. Desalination Water Treat. 2015, 54, 2100-2107. [CrossRef]

6. Mohanty, D. Conventional as well as Emerging Arsenic Removal Technologies-A Critical Review. Water Air Soil Pollut. 2017, 228, 381. [CrossRef]

7. World Health Organization. Arsenic in Drinking Water. 2001. Available online: http://www.who.int/inffs/en/fact210.html (accessed on 12 September 2021).

8. Khan, A.H.; Rasul, S.B.; Munir, A.K.M.; Habibuddowla, M.; Alauddin, M.; Newaz, S.S.; Hussam, A. Appraisal of a simple arsenic removal method for ground water of Bangladesh. J. Environ. Sci. Health Part A 2000, 35, 1021-1041. [CrossRef]

9. Arsenic Contamination in Ground Water in India. Available online: https://vikaspedia.in/energy/environment/know-yourenvironment/water/arsenic-contamination-in-ground-water-in-india (accessed on 12 September 2021).

10. Phok, R.; Nandalal, K.D.W.; Pitawala, H.M.T.G.; Dharmagunawardhane, H.; Weerakoon, S. Arsenic Contamination in Cambodia: A Status Review. 2018. Available online: https://www.academia.edu/34037120/Arsenic_Contamination_in_Cambodia (accessed on 12 September 2021).

11. Kim, M.-J.; Ahn, K.-H.; Jung, Y. Distribution of inorganic arsenic species in mine tailings of abandoned mines from Korea. Chemosphere 2002, 49, 307-312. [CrossRef]

12. Smedley, P.L.; Kinniburgh, D.G. A review of the source, behaviour and distribution of arsenic in natural waters. Appl. Geochem. 2002, 17, 517-568. [CrossRef]

13. Mandal, B.K.; Suzuki, K.T. Arsenic round the world: A review. Talanta 2002, 58, 201-235. [CrossRef]

14. Ungureanu, G.; Santos, S.; Boaventura, R.; Botelho, C. Arsenic and antimony in water and wastewater: Overview of removal techniques with special reference to latest advances in adsorption. J. Environ. Manag. 2015, 151, 326-342. [CrossRef]

15. Issa, N.B.; Rajaković-Ognjanović, V.N.; Marinković, A.D.; Rajaković, L.V. Separation and determination of arsenic species in water by selective exchange and hybrid resins. Anal. Chim. Acta 2011, 706, 191-198. [CrossRef]

16. Larios, R.; Fernández-Martínez, R.; LeHecho, I.; Rucandio, I. A methodological approach to evaluate arsenic speciation and bioaccumulation in different plant species from two highly polluted mining areas. Sci. Total Environ. 2012, 414, 600-607. [CrossRef]

17. Smith, A.H.; Marshall, G.; Yuan, Y.; Ferreccio, C.; Liaw, J.; Ehrenstein, O.V.; Steinmaus, C.; Bates, M.N.; Selvin, S. Increased Mortality from Lung Cancer and Bronchiectasis in Young Adults after Exposure to Arsenic in Uteroand in Early Childhood. Environ. Health Perspect. 2006, 114, 1293-1296. [CrossRef]

18. Gu, Z.; Fang, J.; Deng, B. Preparation and Evaluation of GAC-Based Iron-Containing Adsorbents for Arsenic Removal. Environ. Sci. Technol. 2005, 39, 3833-3843. [CrossRef]

19. Vitela-Rodriguez, A.V.; Rangel-Mendez, J.R. Arsenic removal by modified activated carbons with iron hydro(oxide) nanoparticles. J. Environ. Manag. 2013, 114, 225-231. [CrossRef]

20. Muñiz, G.; Fierro, V.; Celzard, A.; Furdin, G.; Gonzalez-Sánchez, G.; Ballinas, M.L. Synthesis, characterization and performance in arsenic removal of iron-doped activated carbons prepared by impregnation with Fe(III) and Fe(II). J. Hazard. Mater. 2009, 165, 893-902. [CrossRef] 
21. Chen, W.; Parette, R.; Zou, J.; Cannon, F.S.; Dempsey, B.A. Arsenic removal by iron-modified activated carbon. Water Res. 2007, 41, 1851-1858. [CrossRef] [PubMed]

22. Mondal, M.K.; Garg, R. A comprehensive review on removal of arsenic using activated carbon prepared from easily available waste materials. Environ. Sci. Pollut. Res. 2017, 24, 13295-13306. [CrossRef]

23. Xiong, Y.; Tong, Q.; Shan, W.; Xing, Z.; Wang, Y.; Wen, S.; Lou, Z. Arsenic transformation and adsorption by iron hydroxide/manganese dioxide doped straw activated carbon. Appl. Surf. Sci. 2017, 416, 618-627. [CrossRef]

24. Kalaruban, M.; Loganathan, P.; Nguyen, T.V.; Nur, T.; Hasan Johir, M.A.; Nguyen, T.H.; Trinh, M.V.; Vigneswaran, S. Ironimpregnated granular activated carbon for arsenic removal: Application to practical column filters. J. Environ. Manag. 2019, 239, 235-243. [CrossRef] [PubMed]

25. Velazquez-Jimenez, L.H.; Arcibar-Orozco, J.A.; Rangel-Mendez, J.R. Overview of As(V) adsorption on Zr-functionalized activated carbon for aqueous streams remediation. J. Environ. Manag. 2018, 212, 121-130. [CrossRef] [PubMed]

26. Liu, Z.; Zhang, F.-S.; Sasai, R. Arsenate removal from water using Fe3O4-loaded activated carbon prepared from waste biomass. Chem. Eng. J. 2010, 160, 57-62. [CrossRef]

27. Ryu, S.-R.; Jeon, E.-K.; Yang, J.-S.; Baek, K. Adsorption of As(III) and As(V) in groundwater by Fe-Mn binary oxide-impregnated granular activated carbon (IMIGAC). J. Taiwan Inst. Chem. Eng. 2017, 72, 62-69. [CrossRef]

28. Gong, X.-J.; Li, Y.-S.; Dong, Y.-Q.; Li, W.-G. Arsenic adsorption by innovative iron/calcium in-situ-impregnated mesoporous activated carbons from low-temperature water and effects of the presence of humic acids. Chemosphere 2020, $250,126275$. [CrossRef]

29. Nieto-Delgado, C.; Gutiérrez-Martínez, J.; Rangel-Méndez, J.R. Modified activated carbon with interconnected fibrils of ironoxyhydroxides using $\mathrm{Mn}^{2+}$ as morphology regulator, for a superior arsenic removal from water. J. Environ. Sci. 2019, 76, 403-414. [CrossRef]

30. Wang, H.; Cui, L.-F.; Yang, Y.; Sanchez Casalongue, H.; Robinson, J.T.; Liang, Y.; Cui, Y.; Dai, H. Mn3O4-Graphene Hybrid as a High-Capacity Anode Material for Lithium Ion Batteries. J. Am. Chem. Soc. 2010, 132, 13978-13980. [CrossRef]

31. Mondal, P.; Majumder, C.B.; Mohanty, B. Laboratory based approaches for arsenic remediation from contaminated water: Recent developments. J. Hazard. Mater. 2006, 137, 464-479. [CrossRef] [PubMed]

32. Chandra, V.; Park, J.; Chun, Y.; Lee, J.W.; Hwang, I.-C.; Kim, K.S. Water-Dispersible Magnetite-Reduced Graphene Oxide Composites for Arsenic Removal. ACS Nano 2010, 4, 3979-3986. [CrossRef] [PubMed]

33. Wen, Z.; Zhang, Y.; Dai, C.; Chen, B.; Guo, S.; Yu, H.; Wu, D. Synthesis of ordered mesoporous iron manganese bimetal oxides for arsenic removal from aqueous solutions. Microporous Mesoporous Mater. 2014, 200, 235-244. [CrossRef]

34. Liu, X.; Ao, H.; Xiong, X.; Xiao, J.; Liu, J. Arsenic Removal from Water by Iron-Modified Bamboo Charcoal. Water Air Soil Pollut. 2012, 223, 1033-1044. [CrossRef]

35. Guo, Y.; Rockstraw, D.A. Physicochemical properties of carbons prepared from pecan shell by phosphoric acid activation. Bioresour. Technol. 2007, 98, 1513-1521. [CrossRef]

36. Namduri, H.; Nasrazadani, S. Quantitative analysis of iron oxides using Fourier transform infrared spectrophotometry. Corros. Sci. 2008, 50, 2493-2497. [CrossRef]

37. Karagöz, S.; Tay, T.; Ucar, S.; Erdem, M. Activated carbons from waste biomass by sulfuric acid activation and their use on methylene blue adsorption. Bioresour. Technol. 2008, 99, 6214-6222. [CrossRef] [PubMed]

38. Sricharoenchaikul, V.; Pechyen, C.; Aht-ong, D.; Atong, D. Preparation and Characterization of Activated Carbon from the Pyrolysis of Physic Nut (Jatropha curcas L.) Waste. Energy Fuels 2008, 22, 31-37. [CrossRef]

39. Hashim, M.A.; Kundu, A.; Mukherjee, S.; Ng, Y.-S.; Mukhopadhyay, S.; Redzwan, G.; Sen Gupta, B. Arsenic removal by adsorption on activated carbon in a rotating packed bed. J. Water Process Eng. 2019, 30, 100591. [CrossRef]

40. Shu, J.; Cheng, S.; Xia, H.; Zhang, L.; Peng, J.; Li, C.; Zhang, S. Copper loaded on activated carbon as an efficient adsorbent for removal of methylene blue. RSC Adv. 2017, 7, 14395-14405. [CrossRef]

41. Khalili, N.R.; Campbell, M.; Sandi, G.; Golaś, J. Production of micro- and mesoporous activated carbon from paper mill sludge: I. Effect of zinc chloride activation. Carbon 2000, 38, 1905-1915. [CrossRef]

42. Hu, Z.-P.; Gao, Z.-M.; Liu, X.; Yuan, Z.-Y. High-surface-area activated red mud for efficient removal of methylene blue from wastewater. Adsorpt. Sci. Technol. 2018, 36, 62-79. [CrossRef]

43. Budinova, T.; Savova, D.; Tsyntsarski, B.; Ania, C.O.; Cabal, B.; Parra, J.B.; Petrov, N. Biomass waste-derived activated carbon for the removal of arsenic and manganese ions from aqueous solutions. Appl. Surf. Sci. 2009, 255, 4650-4657. [CrossRef]

44. Tuna, A.Ö.A.; Özdemir, E.; Şimşek, E.B.; Beker, U. Removal of As(V) from aqueous solution by activated carbon-based hybrid adsorbents: Impact of experimental conditions. Chem. Eng. J. 2013, 223, 116-128. [CrossRef]

45. Zhang, F.S.; Itoh, H. Iron oxide-loaded slag for arsenic removal from aqueous system. Chemosphere 2005, 60, 319-325. [CrossRef]

46. Wang, Y.; Liu, H.; Wang, S.; Li, X.; Wang, X.; Jia, Y. Simultaneous removal and oxidation of arsenic from water by $\delta-\mathrm{MnO}_{2}$ modified activated carbon. J. Environ. Sci. 2020, 94, 147-160. [CrossRef]

47. Yadava, V.; Tiwaria, D.; Bhagata, M.J.D.; TREATMENT, W. Isotherm, kinetics and thermodynamic parameters study of arsenic (III) and copper (II) adsorption onto Limonia acidissima shell carbon. Desalination Water Treat. 2020, 184, 214-224. [CrossRef]

48. Koohzad, E.; Jafari, D.; Esmaeili, H. Adsorption of Lead and Arsenic Ions from Aqueous Solution by Activated Carbon Prepared from Tamarix Leaves. ChemistrySelect 2019, 4, 12356-12367. [CrossRef] 
49. Pawar, R.R.; Kim, M.; Kim, J.-G.; Hong, S.-M.; Sawant, S.Y.; Lee, S.M. Efficient removal of hazardous lead, cadmium, and arsenic from aqueous environment by iron oxide modified clay-activated carbon composite beads. Appl. Clay Sci. 2018, 162, 339-350. [CrossRef]

50. Kumar, D.; Gaur, J.P. Chemical reaction- and particle diffusion-based kinetic modeling of metal biosorption by a Phormidium sp.-dominated cyanobacterial mat. Bioresour. Technol. 2011, 102, 633-640. [CrossRef] [PubMed]

51. Ho, Y.-S. Review of second-order models for adsorption systems. J. Hazard. Mater. 2006, 136, 681-689. [CrossRef] [PubMed]

52. Zhu, J.; Baig, S.A.; Sheng, T.; Lou, Z.; Wang, Z.; Xu, X. $\mathrm{Fe}_{3} \mathrm{O}_{4}$ and $\mathrm{MnO}_{2}$ assembled on honeycomb briquette cinders (HBC) for arsenic removal from aqueous solutions. J. Hazard. Mater. 2015, 286, 220-228. [CrossRef] [PubMed]

53. Luo, X.; Wang, C.; Luo, S.; Dong, R.; Tu, X.; Zeng, G. Adsorption of As (III) and As (V) from water using magnetite Fe ${ }_{3} \mathrm{O}_{4}$-reduced graphite oxide- $\mathrm{MnO}_{2}$ nanocomposites. Chem. Eng. J. 2012, 187, 45-52. [CrossRef]

54. Cooper, A.M.; Hristovski, K.D.; Möller, T.; Westerhoff, P.; Sylvester, P. The effect of carbon type on arsenic and trichloroethylene removal capabilities of iron (hydr)oxide nanoparticle-impregnated granulated activated carbons. J. Hazard. Mater. 2010, 183, 381-388. [CrossRef] [PubMed]

55. Ociński, D.; Jacukowicz-Sobala, I.; Mazur, P.; Raczyk, J.; Kociołek-Balawejder, E. Water treatment residuals containing iron and manganese oxides for arsenic removal from water-Characterization of physicochemical properties and adsorption studies. Chem. Eng. J. 2016, 294, 210-221. [CrossRef]

56. Karmacharya, M.S.; Gupta, V.K.; Tyagi, I.; Agarwal, S.; Jha, V.K. Removal of As(III) and As(V) using rubber tire derived activated carbon modified with alumina composite. J. Mol. Liq. 2016, 216, 836-844. [CrossRef]

57. Wang, C.; Luo, H.; Zhang, Z.; Wu, Y.; Zhang, J.; Chen, S. Removal of As(III) and As(V) from aqueous solutions using nanoscale zero valent iron-reduced graphite oxide modified composites. J. Hazard. Mater. 2014, 268, 124-131. [CrossRef]

58. Gu, Z.; Deng, B.; Yang, J. Synthesis and evaluation of iron-containing ordered mesoporous carbon (FeOMC) for arsenic adsorption. Microporous Mesoporous Mater. 2007, 102, 265-273. [CrossRef]

59. Shih, Y.-J.; Huang, R.-L.; Huang, Y.-H. Adsorptive removal of arsenic using a novel akhtenskite coated waste goethite. J. Clean. Prod. 2015, 87, 897-905. [CrossRef]

60. Rusmin, R.; Sarkar, B.; Liu, Y.; McClure, S.; Naidu, R. Structural evolution of chitosan-palygorskite composites and removal of aqueous lead by composite beads. Appl. Surf. Sci. 2015, 353, 363-375. [CrossRef]

61. Yao, S.; Liu, Z.; Shi, Z. Arsenic removal from aqueous solutions by adsorption onto iron oxide/activated carbon magnetic composite. J. Environ. Health Sci. Eng. 2014, 12, 58. [CrossRef]

62. Biswas, B.K.; Inoue, J.-I.; Inoue, K.; Ghimire, K.N.; Harada, H.; Ohto, K.; Kawakita, H. Adsorptive removal of As(V) and As(III) from water by a $\mathrm{Zr}(\mathrm{IV})$-loaded orange waste gel. J. Hazard. Mater. 2008, 154, 1066-1074. [CrossRef]

63. Sandoval, R.; Cooper, A.M.; Aymar, K.; Jain, A.; Hristovski, K. Removal of arsenic and methylene blue from water by granular activated carbon media impregnated with zirconium dioxide nanoparticles. J. Hazard. Mater. 2011, 193, 296-303. [CrossRef] 